\title{
Management of Sinus Infection After Immediate Implant Placement with Sinus Lift (Lateral Approach): Case Report
}

\author{
Sang-Chang Lee, DDS, MSD ${ }^{1,2 *}$, Young-Min Shin, DDS, MSD ${ }^{3}$ \\ 'Doctoral Student, Department of Oral \& Maxillofacial Surgery, School of Dentistry, Kyungpook National \\ University, Daegu, Korea \\ ${ }^{2}$ Specialist, BYseokgye Dental Clinic, Nowon, Korea \\ ${ }^{3}$ Assistant Professor of Department of Dentistry(Oral\&maxillofacial surgery), Dongsan medical center, Keimyung \\ university, School of medicine, Dalseogu, Dalgubeoldaero, Daegu, Korea \\ *Corresponding author: Sang-Chang Lee, BYseokgye Denal Clinic, 2 Seokgye-ro, Nowon-gu, Seoul 01895, \\ Korea \\ Tel : +82-2-912-2275. Fax : +82-2-914-2275. E-mail : 1sc7535@hanmail.net
}

OPEN ACCESS

pISSN 2765-7833

eISSN 2765-7841

Journal of implantology and applied sciences 2021; 25(4): 201-208

https://doi.org/10.32542/implantology.2021021

Received: September 6, 2021

Revised: December 3, 2021

Accepted: December 13, 2021

ORCID

Sang-Chang Lee

http://orcid.org/0000-0003-4471-1958

Young-Min Shin

http://orcid.org/0000-0003-2045-2234

Copyright $(\subset$ 2021. The Korean Academy of Oral \& Maxillofacial Implantology \footnotetext{
(c) (7) \$) This is an Open Access article Creative Commons Attribution Non-Commercial License (http://creativecommons. org/licenses/by-nc/4.0/) which permits unrestricted non-commercial use, distribution, and reproduction in any medium, provided the original work is properly cited.
}

\section{Abstract}

This report describes the case of a patient who underwent acute sinus infection after dental implant placement with sinus lift. The implant was placed at the right maxillary second molar area, and the sinus lift with lateral approach was performed. After one week, acute sinusitis was caused in the right maxillary sinus. After the fixture and infected material were removed, sinus irrigation, membrane repair, and implant placement were performed simultaneously. This article reports a complication by iatrogenic cause of a routinely performed dental implant procedure and discusses management of sinusitis occurring by membrane perforation.

Keywords: Immediate implant, Perforation, Schneiderian membrane, Sinusitis, Sinus lift

\section{I . Introduction}

The sinus lift was first described in 1974 and later published in $1986 .{ }^{1}$ The sinus lift procedure has proven to be a predictable and safe procedure. ${ }^{2}$ According to several studies, the sufficient bone height allow the immediate implant placement at the same time with the sinus bone augmentation procedure. ${ }^{3}$ With sinus augmentation, if primary stability is achieved in the residual bone, an implant can be placed simultaneously, even with the lateral opening approach. ${ }^{4}$ But there are the complications in this surgical procedure. The complications can include acute maxillary sinusitis, ${ }^{5}$ wound dehiscence, ${ }^{6}$ and Schneiderian membrane perforations. ${ }^{7}$ From among these, the most common type of complication reported with sinus floor elevation is the perforation of the Schneiderian membrane and the membrane perforation is considered as a potential risk factor for sinus infection and 
implant failure. ${ }^{8}$ Several clinical studies have reported that the perforation was strongly associated with the occurrence of postoperative sinus infection. ${ }^{9}$ The incidence of the membrane perforation has been reported to range from 11 to $56 \%$ in previous studies. ${ }^{10,11}$ If the membrane perforation is occurred, treatment using fibrin sealant, suturing, and bio-absorbable membranes can be used. ${ }^{10,11}$

This case report describes patient with the acute sinusitis after immediate implant placement with sinus lift because of the sinus membrane perforation and proposes a suture technique to repair the membrane perforation.

\section{II . Case Report}

A 64-year-old man presented with a history of the severe pain and food packing of the right maxillary second molar. Clinical and radiological evaluation revealed a root caries of the right maxillary second molar (Fig. 1). The patient had the history of controlled hypertension and he was a heavy smoker (about 1 pack per a day). It was diagnosed with cemental caries on the right maxillary second molar and the immediate implant placement with sinus lift (window approach) was scheduled under local anesthesia because of gaining primary stability through inter-septal bone and the inferior wall of the sinus. Local anesthesia was carried out with 2\% lidocaine containing 1:100,000 epinephrine (Huons Co., Seongnam, Korea). One vertical incision was made at mesial end of the horizontal incision.

The right maxillary second and third molars were extracted. A lateral bony window was prepared, and the sinus membrane was thoroughly lifted from the sinus floor with bony window lifted upward and inward. But the mesial aspect of the lifted sinus membrane was perforated (about $4-5 \mathrm{~mm}$ ). A collagen wound dressing (Colla-tape ${ }^{\circledR}$; Zimmer Dental Carlsbad, CA, USA) was used for the repair of the sinus membrane perforation (Fig. 2). Alloplastic bone-grafting material (A-oss ${ }^{\circledR}$; Osstem implant Co., Seoul, Korea) was packed and the implant placement (Superline ${ }^{\circledR}$; Dentium implant Co., Seoul, Korea) was

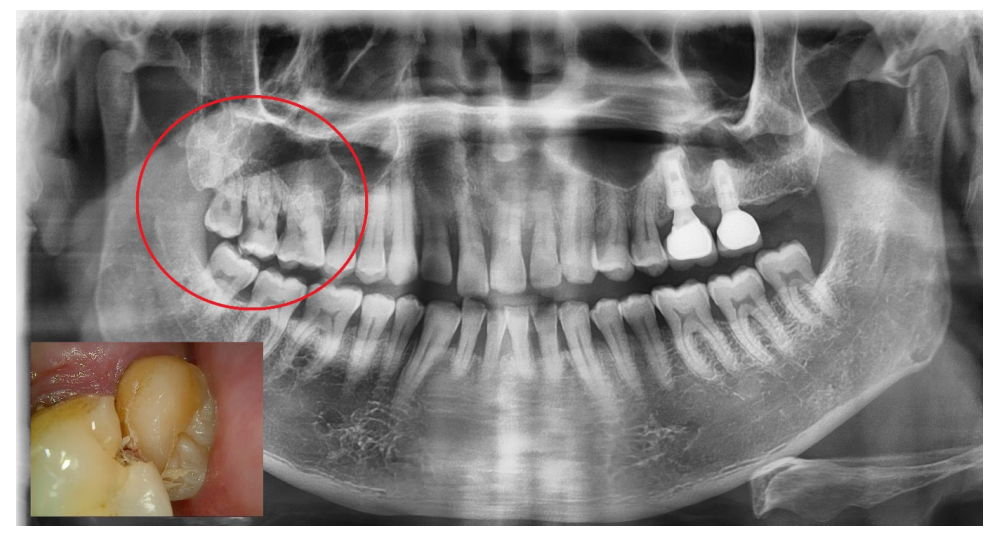

Fig. 1. Root caries on the right maxillary $2^{\text {nd }}$ molar (Red circle). 
performed (Fig. 3). After 7 days, the patient had pain, nasal discharge and foul odor on the right paranasal area. Under local anesthesia, the flap was elevated. The infected bone material, fixture, collagen wound dressing and infected tissue were removed (Fig. 4). Sinus irrigation was performed for about 5 minutes, until the foul odor and the blockage of ostium disappeared. During this procedure, the size of perforation got bigger by about $1 \mathrm{~cm}$.

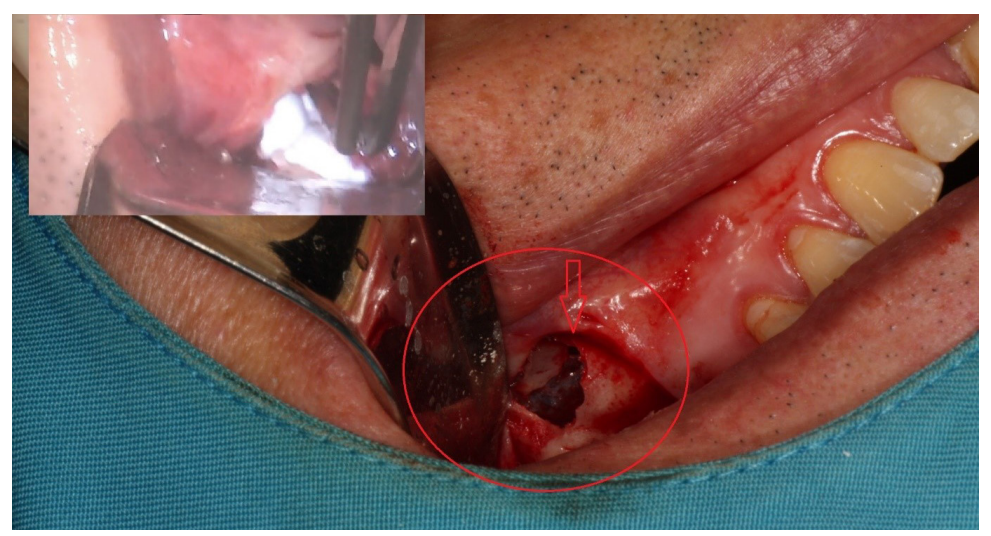

Fig. 2. Window opening (Red arrow: membrane perforation).

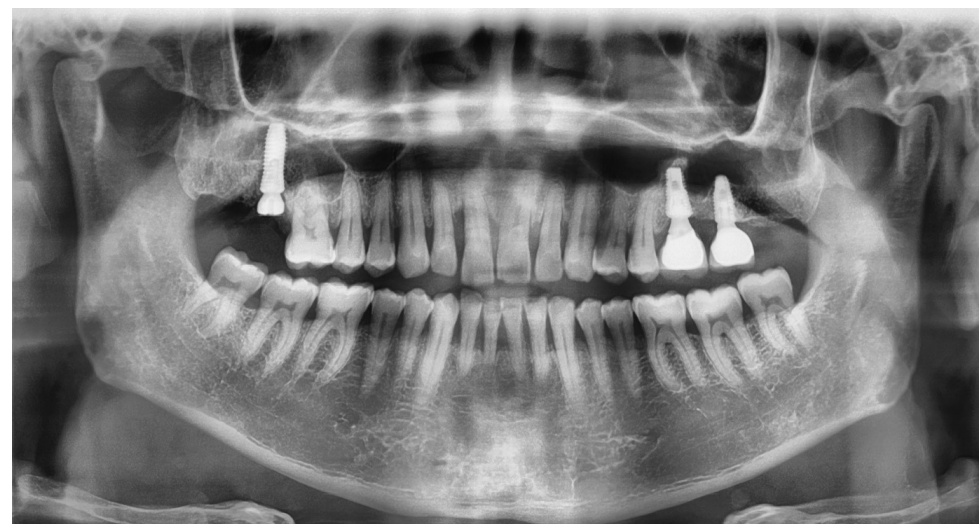

Fig. 3. Post-operative panoramic view.

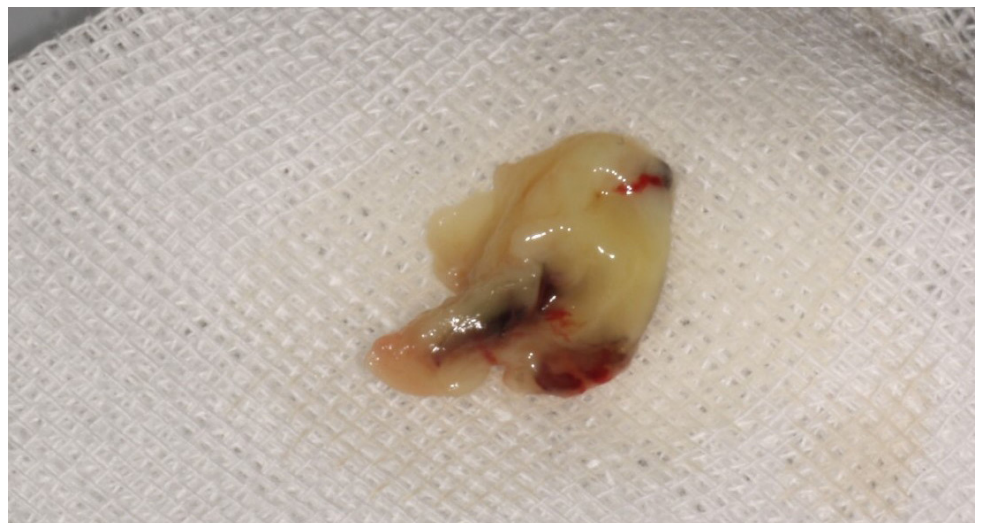

Fig. 4. Infected tissue. 
After the stuffy nose on the right side was completely gone, the bony window was extended anteriorly and the sinus membrane around perforated area was lifted. The perforated membrane was sutured (Rexlon nylon 4- $0^{\circledR}$; SM eng, Seoul, Korea) and the collagen wound dressing was inserted for the complete sealing (Fig. 5). Alloplastic bone-grafting material (A-oss ${ }^{\circledR}$; Osstem implant Co., Seoul, Korea) was packed and the implant placement (Superline ${ }^{\circledR}$; Dentium implant Co., Seoul, Korea) was performed immediately (Fig. 6). After operation, conservative treatment (augmentin $625 \mathrm{mg}$, acidified pseudo ephedrine HCL $2.5 \mathrm{mg}$, acetaminophen $500 \mathrm{mg}, 3$ times daily) continued for 1 week. After one week,

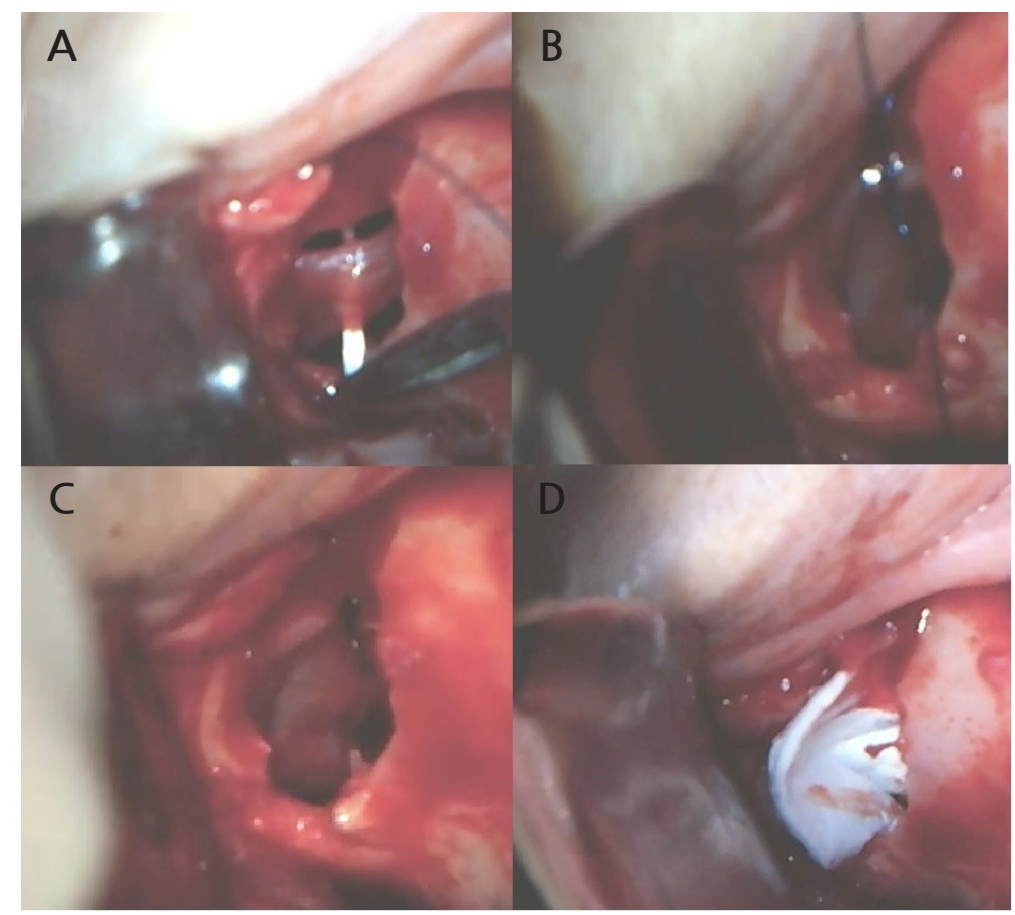

Fig. 5. (A) Perforated membrane, (B) Suturing of the perforated membrane, (C) After suturing, (D) Application of collagen wound dressing (Colla-tape ${ }^{\circledR}$ ) for better closure.

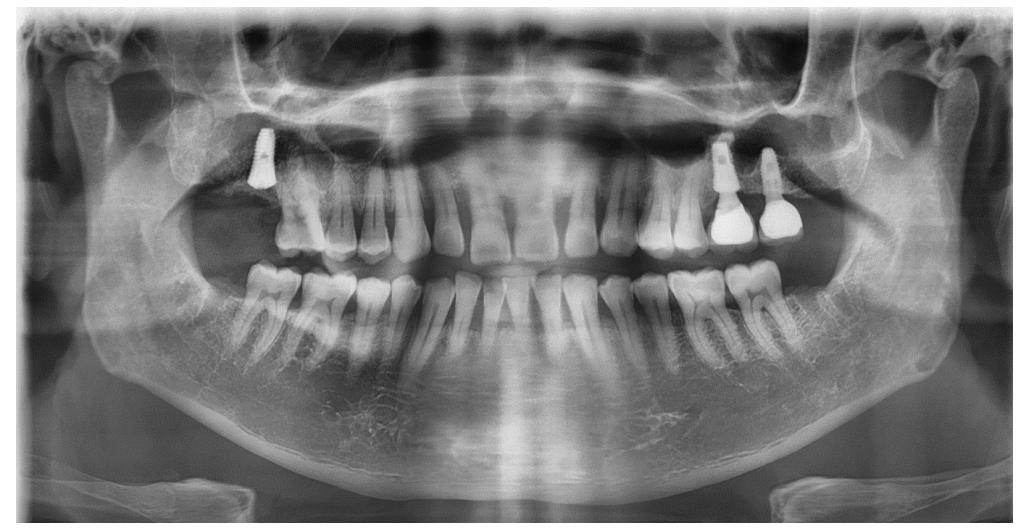

Fig. 6. Post-operative panoramic view (re-implant placement). 
the suture was removed and the discomfort symptom was disappeared. After 3 months later, occlusal loading started (Fig. 7). In the 3-months follow-up, the implant and lifted sinus bone formation were stable (Fig. 8). In the 2-years follow-up, the implant was left stable and the sinus lifted bone was maintained well (about $6 \mathrm{~mm}$ height) (Fig. 9).

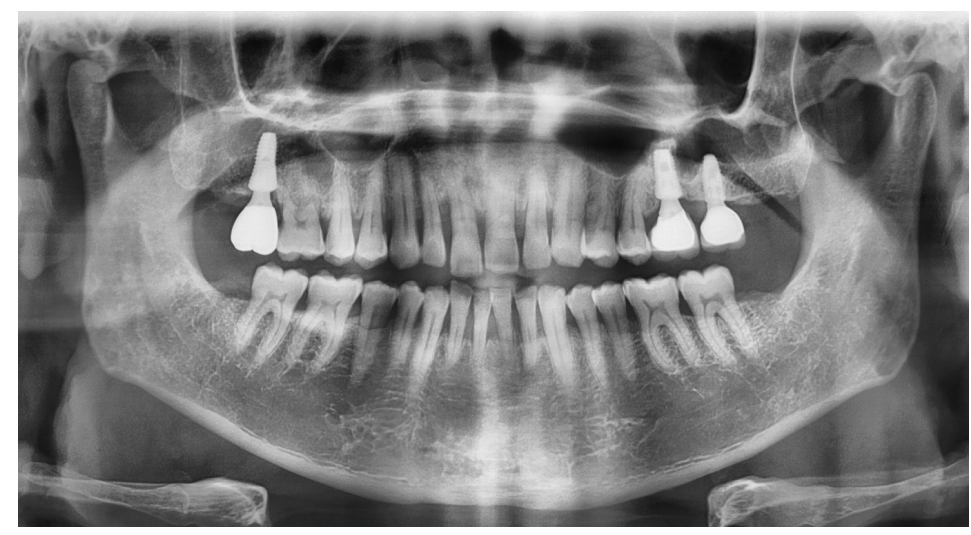

Fig. 7. Post-loading panoramic view.

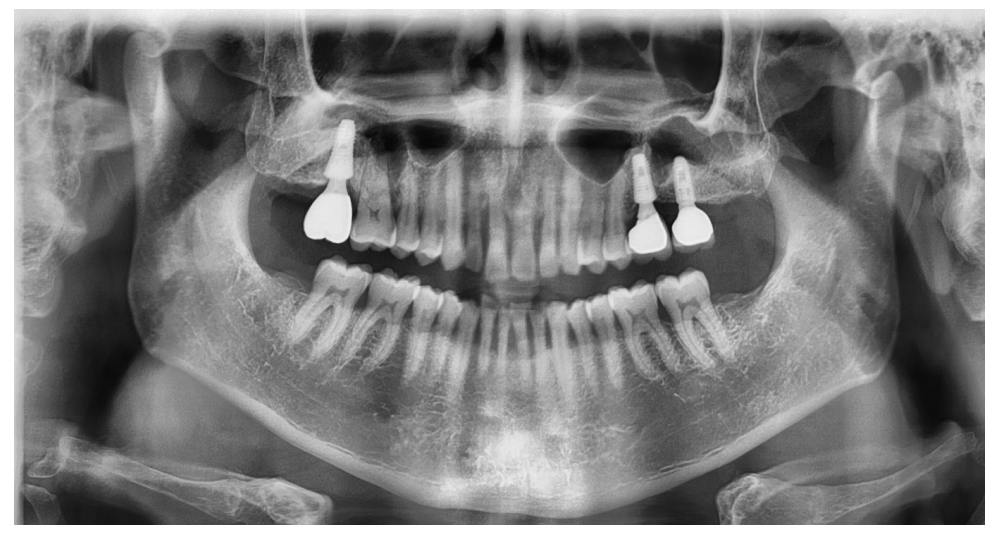

Fig. 8. 3-months follow-up panoramic view.

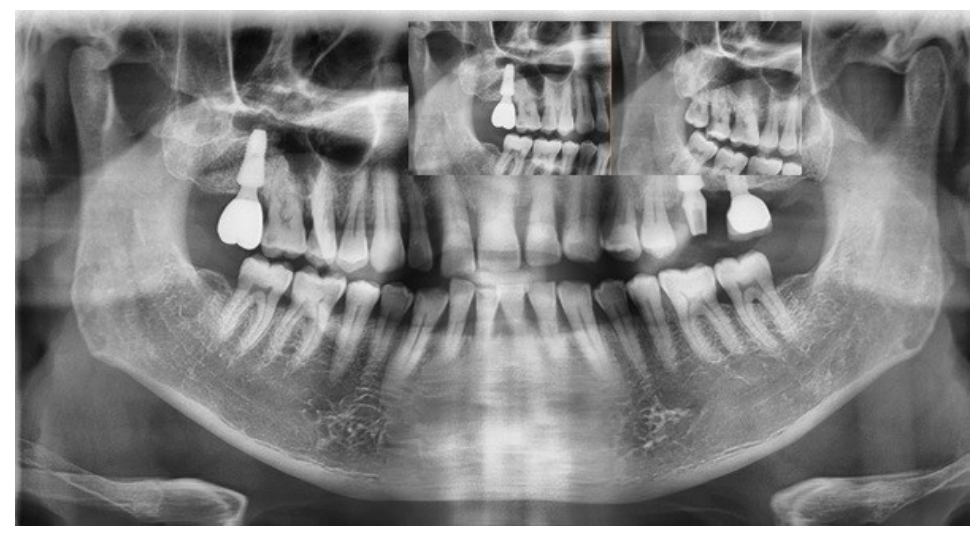

Fig. 9. 2-years follow-up panoramic view. 


\section{Discussion}

The maxillary sinus lift is a procedure to increase the quantity of bone. The sinus elevation procedure is considered a safe and predictable treatment with minor complications. ${ }^{1}$ Although this procedure is a reliable method, many complications could occur. Among these, the occurrence of sinus membrane perforation has been reported to be a common complication. There are many risk factors for perforation such as sinus floor irregularities, septa, the existence of a thin membrane, previous sinus operations, adhesion of the Schneiderian membrane and the absence of bone between the sinus mucosa and oral mucosa. ${ }^{12,13}$ Although some study reported that minor membrane perforation might not represent a significant clinical hazard, ${ }^{14}$ a large perforation should be repaired because of its possible sequelae, such as sinusitis and failure of the graft. Proussaefs et al. reported that the perforated sinuses displayed less vital bone formation than non-perforated sinuses. ${ }^{15}$ There are many studies and reports on repair techniques. But most recommend delayed installation of the dental implant. On the other hand, some reports propose that bone grafting would not be affected if the repair is adequate..$^{15,16}$

In this study, the author performed simultaneous implantation, although there was perforation. The repair technique may be vary depending on the size of the membrane perforation. If a membrane perforation is $<2 \mathrm{~mm}$ in diameter, it is not typically cause for concern and will not usually require any special treatment. ${ }^{16}$ If the perforation is larger, it needs to be closed and covered to prevent loss of the graft and secondary complication such as sinusitis. ${ }^{17}$ In large perforation, the collagen membrane that covered the perforation could not be supported by surrounding intact sinus membrane. Therefore it is impossible to maintain the position of the collagen membrane. Large membrane perforations often require complex repairs. ${ }^{18,19}$ Various methods can be used for the treatment of membrane perforation. In case of small perforation $(<5 \mathrm{~mm})$, the perforated membrane can be managed by using tissue fibrin glue, suturing or by covering it with a restorable barrier membrane. In case of large perforation $(>5 \mathrm{~mm})$, larger barrier membranes, lamellar bone plates or suturing either alone or in combination with fibrin glue can be used. ${ }^{12}$ In this case, the perforated membrane was repaired with suture and collagen wound dressing. Many authors did not recommend membrane suturing technique because of the extremely delicate features of the membrane. Also, the suture of the membrane can be enlarge the existing perforation or create a new one. ${ }^{18}$ And as in this case, the window can be opened wider and the membrane should be lifted wider in the process of approaching and preparing for suture. But if the approach is possible and the membrane is not too thin, suturing technique is an easy way to recover the membrane perforation. In this case, the size of the perforation was about $5 \mathrm{~mm}$ in the first operation. The membrane was repaired with collagen wound dressing. However, infection occurred in the perforated area. In order to shorten the treatment period and for the management of the patient, the infection source and implant were removed, and at the same time, the sinus membrane repair using suture (Rexlon nylon 4- $0^{\circledR}$; SM 
eng, Seoul, Korea) was performed. ${ }^{20}$ The suturing membrane was used successfully for the closure of the perforation and dental implant was placed simultaneously. There were no serious infections. And clinical and radiographic findings at the 2-year follow up were adequate (Fig. 9).

\section{Conclusion}

The maxillary sinus lift is a predictable procedure for the implant placement of atrophic maxillary posterior area. But the intraoperative complication can be lead to the failure of the osseointegration. Among these, the perforation of sinus membrane is reported to be a common complication. Depending on the size and position of perforation, there are numerous repair technique. In this case, a collagen wound dressing was used for the repair of the sinus membrane perforation during first operation. But maxillary sinus infection was occurred. In second operation, sinus irrigation and curettage was performed and the perforated sinus membrane was sutured. The implant was osseointegrated, and no complications were observed.

\section{References}

1. Tantum Jr H. Maxillary and sinus implant reconstructions. Dent Clin North Am 1986;30:207-29.

2. Pjeturrson BE, Tan WC, Zwahlen M, Lang NP. A systemic reivew of the success of sinus floor elevation and survival of implants inserted in combination with sinus floor elevation. J Clin Periodontol 2008;35:216-40.

3. Rios HF, Avila G, Galindo P, Bratu E, Wang HL. The influence of remaining alveolar bone upon lateral window sinus augmentation implant survival. Implant Dent 2009;18:402-12.

4. Barone A, Santini S, SbordoneL, Crespi R, Covani U. A clinical study of the outcomes and complications associated with maxillary sinus augmentation. Int J Oral Maxillofac Implants 2006;21:81-5.

5. Anavi Y, Allon DM, Avishai G, Calderon S. Complications of maxillary sinus augmentations in a selective series of patients. Oral Surg Oral Med Oral pathol Oral Radiol Endod 2008;106:34-8.

6. Nolan PJ, Freeman K, Kraut RA. Correlation between Schneiderian membrane perforation and sinus lift graft outcome: a retrospective evaluation of 359 augmented sinus. J Oral Maxillofac Surg 2014;72:47-52.

7. Cordioli G, Mazzocco C, Schepers E, Brugnolo E, Majzoub Z. Maxillary sinus floor augmentation using bioactive glass granules and autogenous bone with simultaneous implant placement: clinical and histological findings. Clin Oral Implants Res 2001;12:270-8.

8. Barone A, Santini S, Sbordone L, Crespi R, Covani U. A clinical study of the outcomes and complications associated with maxillary sinus augmentation. Int J Oral Maxillofac Implants 2006;21:81-5.

9. Pikos MA. Maxillary sinus membrane repair: report of a technique for large perforations. Implant 
Dent 1999;8:29-34.

10. Fugazzotto PA, Vlassis J. A simplified classification and repair system for sinus membrane perforations. J Periodontol 2003;74:1534-41.

11. Schwartz-Arad D, Herzberg R, Dolev E. The prevalence of surgical complications of the sinus graft procedure and their impact on implant survival. J Periodontol 2004;75:511-6.

12. Kasabah S, Krug J, Simunek A, Lecaro MC. Can we predict maxillary sinus mucosa perforation? Acta Medica 2003;46:19-23.

13. Becker ST, Terheyden H, Steinriede A, Behrens E, Springer I, Wiltfang J. Prospective observation of 41 perforations of the Schneiderian membrane during sinus floor elevation. Clin Oral Implants Res 2008;19:1285-9.

14. Bonye PJ. Analysis of performance of root-form endosseous implants placed in the maxillary sinus. J Long-Term Eff Med Implants 1993;3:143-59.

15. Proussaefs P, Lozada J, Kim J, Rohrer MD. Repair of the perforated sinus membrane with a resorbable collagne membrane: a human study. Int J Oral Maxillofac Implants 2004;19:413-20.

16. Paulraj B, Ganapathy D, Jain AR. Perforation repair during sinus lift - A review. Drug Invent Today 2019;12:186-8.

17. van den Bergh, JP, ten Bruggenkate CM, Disch FJ, Tuinzing DB. Anatomical aspects of sinus floor elevation. Clin Oral Implants Res 2000;11:256-65.

18. Vlassis JM, Fugazzotto PA. A classification system for sinus membrane perforations during augmentation procedures with options for repair. J Periodontol 1999;70:692-9.

19. Karabuda C, Arisan V, Hakan O. Effects of sinus membrane perforations on the success or dental implants placed in the augmented sinus. J Periodontol 2006;77:1991-7.

20. Im DH, Jang SJ, Kim KA, Baek JA, Ko SO, Shin HK. Repair of the perforated sinus membrane with a micro-suture technique: Report of cases. Maxillofac Plast Reconstr Surg 2007;29:3:241-9. 